\title{
Developed design for line bleeding injection pump: Double-act LBIP
}

\author{
Mohamed Elashmawy ${ }^{1,2, *}$, Mohammad Alnais ${ }^{1}$ \\ ${ }^{1}$ Engineering College, University of Hail, Hail, Saudi Arabia \\ ${ }^{2}$ Engineering Science Department, Faculty of Petroleum and Mining Engineering, Suez University, Suez, Egypt
}

Email address:

arafat_696@yahoo.com (M. Elashmawy),dr_alnais@hotmail.com (M. Alnais)

\section{To cite this article:}

Mohamed Elashmawy, Mohammad Alnais. Developed Design for Line Bleeding Injection Pump: Double-Act LBIP. International Journal of Mechanical Engineering and Applications. Special Issue: Advanced Fluid Power Sciences and Technology. Vol. 3, No. 1-2, 2015 , pp. 11-16. doi: 10.11648/j.ijmea.s.2015030102.12

\begin{abstract}
Injection process is essential for many industrial applications especially in water desalination and water treatment market. The new concept of injection, line bleeding injection pump (LBIP) [8], opens a door for injection processes of simpler and effective injection facilities with relatively low cost and less maintenance requirements. The concept of LBIP is to utilize the pressure inside the line and intensify it to produce higher pressure than the line pressure to inject chemicals inside it. Certain amount of water should be bleed out from the line. The amount of bleed water then could be either recycled back to the line or drained back to the intake. The aim of this study is to develop LBIP design to be double act injection pump. Double-act LBIP design is promising to be more effective and low price design for relatively higher doses injection applications. It has no spring. The developed design will act as two pumps in one unit using very simple design and traditional materials. This concept will take the cost to its minimum value. The double-act LBIP price is promising to be very competitive compared to other injection pump types. Double-act LBIP is equipped with 3 adapters as a simple and accurate variable displacement facility that gives the design a strong potential as metering injection pump with wide range of injection ability (20-1000 liter/day). Both single-act and double-act LBIP designs require no driving power except for the line pressure itself. This concept is promising for researches of developing renewable energy with seawater desalination units in remote areas.
\end{abstract}

Keywords: Injection, Pump, Line Pressure, Double-Act, Line Bleeding

\section{Introduction}

Rapid increase of population and rare of fresh water natural resources is a big challenge in the kingdom of Saudi Arabia. Water needs increases rapidly around the world especially in Saudi Arabia. Water desalination is the main source of drinking water in Saudi Arabia either from sea or wells. According to the Saudi Central Department of Statistics and Information the Saudi Population of 2013 is 29,994,272 people with population growth rate of $2.7 \%$. The United Nations (Population Division) expected 59.7 million people in Saudi Arabia by 2050 [1]. Total world desalination market is around 68 million $\mathrm{m}^{3} / \mathrm{d}$ in 2010 and expected to reach 120 million $\mathrm{m}^{3} / \mathrm{d}$ by 2020 [2]. Saudi Arabia produces around $20 \%$ of the whole amount produced worldwide [3]. Comparing population 2007 (25 million) to 2050 (59.7 million) Saudi Arabia water needs is expected to be increased by almost $240 \%$.
Saudi Arabia has a very big market of water desalination industry. This situation puts Saudi Arabia in a very critical and risky situation concerning water needs and its challenges. So that any achievement in developing water desalination process will lead to great help enhancing Saudi water market potential. Injection process is an essential part of water desalination and treatment process.

The worldwide injection pump common type is the diaphragm injection units because of its simplicity, low precise and compact design. The membrane of the diaphragm injection pump is subjected to high cyclic fatigue and stress at certain spots that cause material failure after some operating period.

In order to satisfy high pressure injection applications, piston pump unite should be used. The main advantage of piston pumps is its high volumetric efficiency due to surface contact between piston and cylinder [4]. 
Watson-Marlow pumps group developed recently a new chemical metering pump (QDOS 60 model). This pump type is designed for high accuracy and low costs chemical metering injection applications. It is suitable for large water treatment plants, fluid level adjusting and monitoring, fluid recovery control, priming of line and intuitive flow calibration [5].

A weak component of pneumatic diaphragm pumps is the diaphragm. The duration time of continuous operation of the pump depends on such weak component which limits pump operating time and requires periodically replacement [6].

A fully magnetic resonance-compatible withdraw/infuse syringe pump is developed and the injector become programed for variable injection rates. This facility permits the rapid and reproducible programmable injection of hyperpolarized material [7].

Recently a new injection concept was developed by Elashmawy. The proposed concept is to utilize the action of hydraulic line pressure to inject the same line with required injection chemical doses. The idea is to intensify line pressure and use it to produce higher pressure in the chemical dose side piston to inject the chemicals in the same line. Some line water should be bleed out through a control valve. A spring action is used for the suction stroke. Two non-return valves are essential components for suction and delivery injection ports. The bleed water is either pumped back to the line or drained back to the intake [8].

\section{Principal of Double-Act LBIP}

The recent new injection concept (LBIP) proposed by Elashmawy is illustrated schematically in Fig. 1 [8].

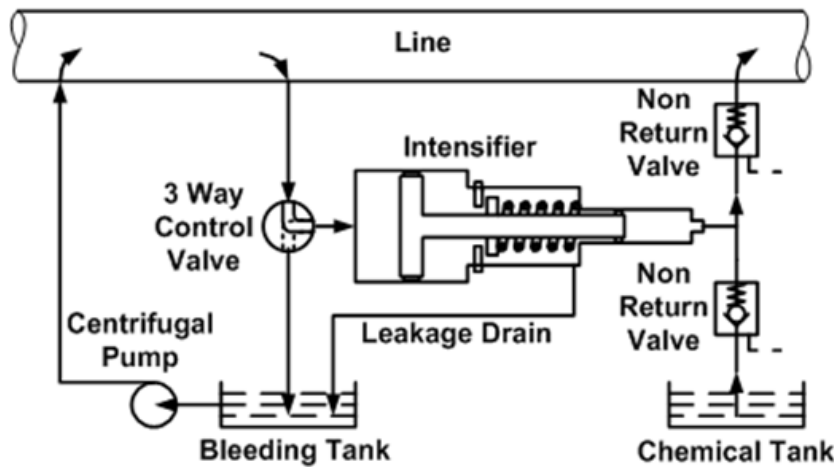

Figure 1. Schematic diagram of single-act LBIP [8].

This design uses one act and one injection piston with spring action for suction stroke. It is suitable for variable displacement control with simple facility of spring stopper that could be adjusted for 8 different positions. Such design is very practical for low dosing applications, while for high dosing requirement multi injection units will be necessary. In order to overcome this problem a double-act design is developed using two injection piston ends and one driving piston mounted in the middle, Fig. 2. The three pistons are on the same shaft. Instead of one 3-way control valve shown in Fig. 1, the developed double-act LBIP needs for two 3-way valves $\left(\mathrm{V}_{1}\right.$ and $\left.\mathrm{V}_{2}\right)$ that are mounted at the same arm with inverse port actions as illustrated in Fig. 2. $\mathrm{V}_{1}$ connects the line pressure into the two sides of driving piston cylinder. $\mathrm{V}_{2}$ connects the driving piston cylinder to the bleeding tank. Fig. 3 shows the main components of the proposed double-act LBIP with numbers from 1 to 16 . The invers situation of $V_{1}$ and $\mathrm{V}_{2}$ satisfies two operating modes as follows:

Mode1: $\mathrm{V}_{1}$ connects line flow to RHS of driving piston cylinder (3), while $\mathrm{V}_{2}$ connects LHS of driving piston cylinder (4) to the bleeding tank. Fig. 2 shows schematic diagram of mode1.

Mode2: $\mathrm{V}_{1}$ connects line flow to LHS of the driving piston cylinder (4), while $\mathrm{V}_{2}$ connects RHS of driving piston cylinder (3) to the bleeding tank.

Mode1 causes piston shaft group moving to the left direction. The left piston end that sealed by rubber sealing (9) acts as delivery piston, while the right piston end that sealed by rubber sealing (8) acts as suction piston. Valves $\mathrm{NV}_{1}$ and $\mathrm{NV}_{4}$ opened, while valves $\mathrm{NV}_{2}$ and $\mathrm{NV}_{3}$ closed. Mode2 behaves simply as an inverse of mode1. This development facility satisfies double flow dosing rates compared to the single-act LBIP. Of course using double-act unit means higher needs of injection doses.

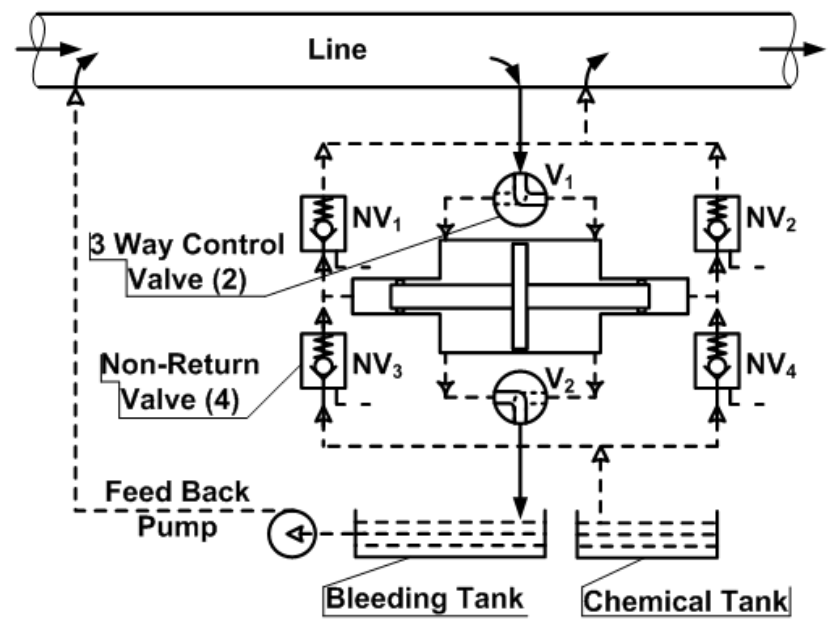

Figure 2. Schematic diagram of developed double-act LBIP, mode1.

Fig. 3 shows detailed 2D-CAD of the proposed developed double-act LBIP. The numbers stated in Fig. 3 are described in Table 1. The proposed design duplicates the single-act LBIP discharge with the same high pressure injection ability.

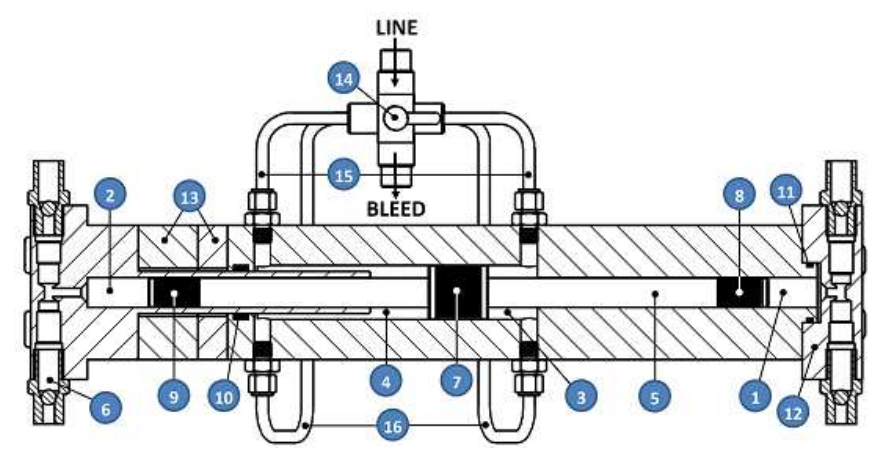

Figure 3. 2D-CAD sectional view for developed design, double-act LBIP. 


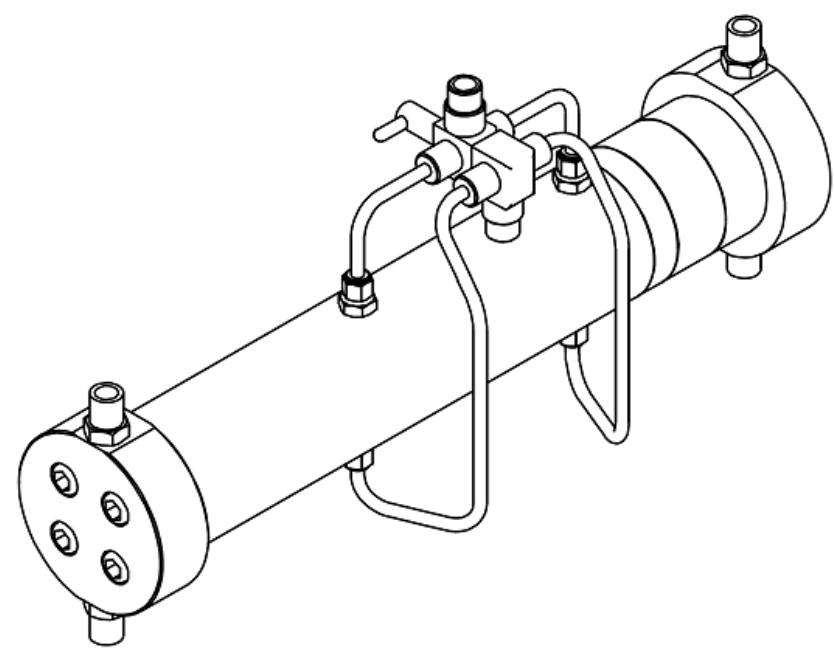

Figure 4. 3D-CAD back view for developed double-act LBIP showing 3-way control valves piping and connections.

Fig. 4 shows 3D back view of the double-act LBIP concentrating on the piping and connections of the two 3-way control valves. The Figure shows also the pump assembly equipped with two adapters $\mathrm{AD}_{1}$ and $\mathrm{AD}_{2}$ enabling pump to work with regulation mode $\mathrm{RM}_{4}$, Table 2 .

Solenoid with electromagnetic control system could be used to control the cyclic speed of the double 3-way control valve (14). Servo motor is also an alternative control system could drive the control valve. Double 3-way control valve consists simply of two inversely mounted 3-way control valves that attached to the same shaft to keep low price advantage and satisfy the required aforementioned two operating modes as follows:

For first LBIP act (Mode1), $\mathrm{V}_{1}$ (14) connects line flow to RHS of driving piston cylinder (3) and opens it to the line pressure $\left(P_{L}\right)$ which applies a force of $F=P_{L} \times\left(A_{L}-A_{I}\right)$. The other piston end will exert the same force to the injection cylinder (2) which applies a pressure of $P_{I}=F / A_{I}$. Where $P_{L}$ : Line Pressure, $P_{I}$ : Injection pressure, $F$ : Piston force, $A_{L}$ : Line-side cross-sectional area, $A_{I}$ : Injection-side cross-sectional area. Mode1 causes none-return valves $\mathrm{NV}_{2}$ and $\mathrm{NV}_{3}$ to be automatically closed while $\mathrm{NV}_{1}$ and $\mathrm{NV}_{4}$ are opened, Fig. 2. The pressure inside injection cylinder (2) is equal to $P_{L} \times\left\{\left(A_{L}-A_{I}\right) / A_{I}\right\}$ which is greater than line pressure by the area ratio of $\left\{\left(A_{L}-A_{I}\right) / A_{I}\right\}$. This valve situation leads the piston to move toward left direction which forces chemical dose trapped in LHS injection cylinder room (2) to be injected out through non-return valve $\mathrm{NV}_{1}$ and the line fluid trapped in room (4) to be drained to the bleeding tank through the 3-way control vale $\mathrm{V}_{2}$. At the same time cylinder, room (1) act as suction room and sucks chemical dose through non-return valve $\mathrm{NV}_{4}$ filling the room with the chemical dose.

At the end of the first act (mode1) the piston will stop at the position that is controlled by 3 adapters $\left(\mathrm{AD}_{1}, \mathrm{AD}_{2}\right.$ and $\mathrm{AD}_{3}$, see Table 2) and keep stopping until the control valve switches to mode2.

In the second LBIP act (mode2) all processes of mode 1 are inversed and room (4) will be opened to the line pressure causes piston to move toward right side direction forcing chemical dose in room (1) to be injected in the line through non- return valve $\mathrm{NV}_{2}$ and the line fluid trapped in room (3) to bleed out to the bleeding tank through 3-way control valve $V_{2}$. Room (2) now acts as a suction room. For each cycle of the control valve $\left(\mathrm{V}_{1}\right.$ and $\left.\mathrm{V}_{2}\right)$ the piston will perform 2 injection actions this where the name double-act comes from. The cyclic speed of switching between mode1 and mode 2 will control the discharge of the double-act LBIP. Pipes group (15) connects the control valve (14) to the two rooms of driving cylinder ( 3 and 4 ) by suitable fittings. While Pipes group (16) connects drain bleeding fluid from the two rooms (3 and 4) to the bleeding tank. After some operating period the bleeding tank will be filled with line fluid. At certain level it could be either pumped back to the line or drained back to the unit intake source.

All parts of the LBIP desig were designed using 3D-CAD SolidWorks. Area ratio of 2.25 was used for the developed double-act LBIP to enable comparison with the single-act design. Increasing area ration will certainly satisfy a strong and fast injection action, but this will be at an expense of line fluid bleeding amount. Area ratio is very important parameter that should be experimentally investigated.

Table 1. Definitions of numbers stated in Fig. 3.

\begin{tabular}{ll}
\hline Item No & Definition \\
\hline 1 & RHS injection cylinder room \\
2 & LHS injection cylinder room \\
3 & RHS driving cylinder room \\
4 & LHS driving cylinder room \\
5 & Piston \\
6 & Non-return valves (4 valves) \\
7 & Driving piston seal \\
8 & RHS piston end rubber seal \\
9 & LHS piston end rubber seal \\
10 & Regulation cylinder rubber seal \\
11 & RHS cylinder rubber seal \\
12 & RHS cylinder cover and non-return valves plate \\
13 & 2-adapter cylinders, AD and $_{2}$ \\
14 & Double 3-way control valve \\
15 & Line side piping \\
\hline
\end{tabular}

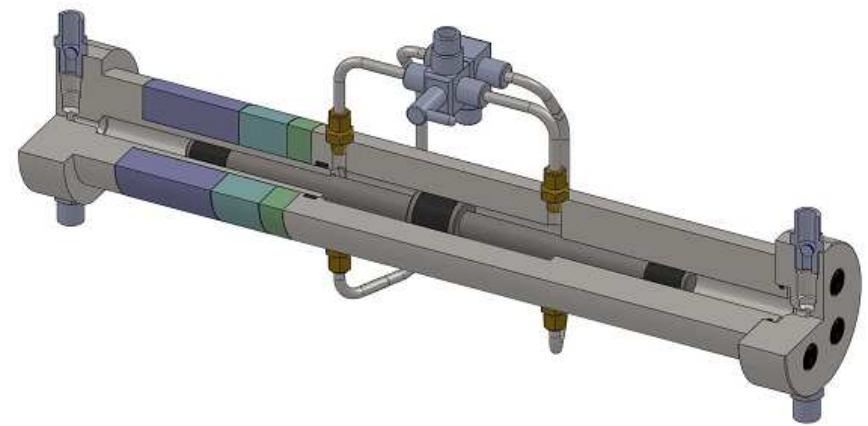

Figure 5. 3D-CAD of developed double-act LBIP design, 1/4 section. 
Fig. 5 shows a 3D half sectional view of the double-act LBIP and Fig. 6 shows a complete isometric outside view of the double-act LBIP showing all the 3 adapters of regulation set, $\mathrm{RM}_{8}$. Variable displacement facility of the double-act LBIP is a simple mechanism that designed to be accurate and strong design for high accurate metering injection applications. Also the pump holding frame is showed in Fig. 6.

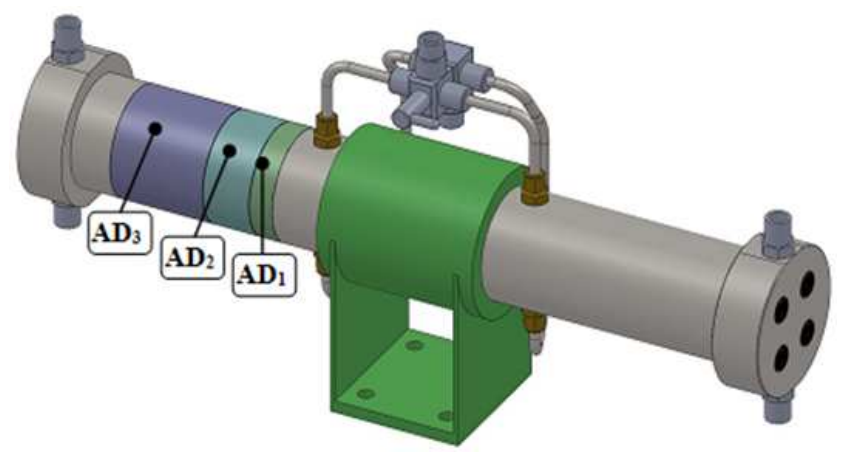

Figure 6. Developed double-act LBIP 3D-CAD assembly, pump complete outlook including all regulation adapters.

Table 2 describes design parameters of the double-act LBIP. The developed pump has simple and accurate variable displacement facility suitable for metering injection. There are eight regulation modes $\left(\mathrm{RM}_{1}, \mathrm{RM}_{2}, \ldots\right.$ and $\left.\mathrm{RM}_{8}\right)$. To satisfy these eight modes only three adapters were designed. $\mathrm{AD}_{1}(10$ mm thick), $\mathrm{AD}_{2}$ (20 mm thick) and $\mathrm{AD}_{3}$ (40 mm thick).

By using only these three adapters with suitable combination tabulated in the last column of Table 2, the costumer can easily choose any regulation mode according to the demand dosing he may needs.

Table 2. Nominal discharge of double-act LBIP for the 8 regulator modes with adapter combinations, regulation valve cyclic speed of 30 cycle /min.

\begin{tabular}{lllll}
\hline $\begin{array}{l}\text { Discharge } \\
\text { lday }\end{array}$ & $\begin{array}{l}\boldsymbol{\Delta V} \\
\mathbf{m l} / \text { Stroke }\end{array}$ & $\begin{array}{l}\boldsymbol{\Delta X} \\
\mathbf{m m}\end{array}$ & $\begin{array}{l}\text { Regulator } \\
\text { Mode }\end{array}$ & $\begin{array}{l}\text { Adapters } \\
\text { Combination }\end{array}$ \\
\hline 33.93 & 0.786 & 5 & $\mathrm{RM}_{1}$ & No adapter \\
101.788 & 2.356 & 15 & $\mathrm{RM}_{2}$ & $\mathrm{AD}_{1}(10 \mathrm{~mm})$ \\
169.646 & 3.926 & 25 & $\mathrm{RM}_{3}$ & $\mathrm{AD}_{2}(20 \mathrm{~mm})$ \\
237.504 & 5.498 & 35 & $\mathrm{RM}_{4}$ & $\mathrm{AD}_{1}+\mathrm{AD}_{2}$ \\
305.362 & 7.068 & 45 & $\mathrm{RM}_{5}$ & $\mathrm{AD}_{3}(40 \mathrm{~mm})$ \\
373.222 & 8.64 & 55 & $\mathrm{RM}_{6}$ & $\mathrm{AD}_{1}+\mathrm{AD}_{3}$ \\
441.08 & 10.21 & 65 & $\mathrm{RM}_{7}$ & $\mathrm{AD}_{2}+\mathrm{AD}_{3}$ \\
508.938 & 11.78 & 70 & $\mathrm{RM}_{8}$ & $\mathrm{AD}_{1}+\mathrm{AD}_{2}+\mathrm{AD}_{3}$ \\
\hline
\end{tabular}

\section{Results and Discussion}

The developed double-act LBIP injection pump provides an easy way of high accurate metering injection with easy and accurate regulation facility. The developed design utilizes the hydraulic power of the line pressure to drive the injection pump. Double-acting concept needs no spring action for suction stroke and requires few mechanical parts and traditional materials that give it great advantage for less maintenance requirements and low price. Table 2 shows the dimensions and nominal pump displacement.

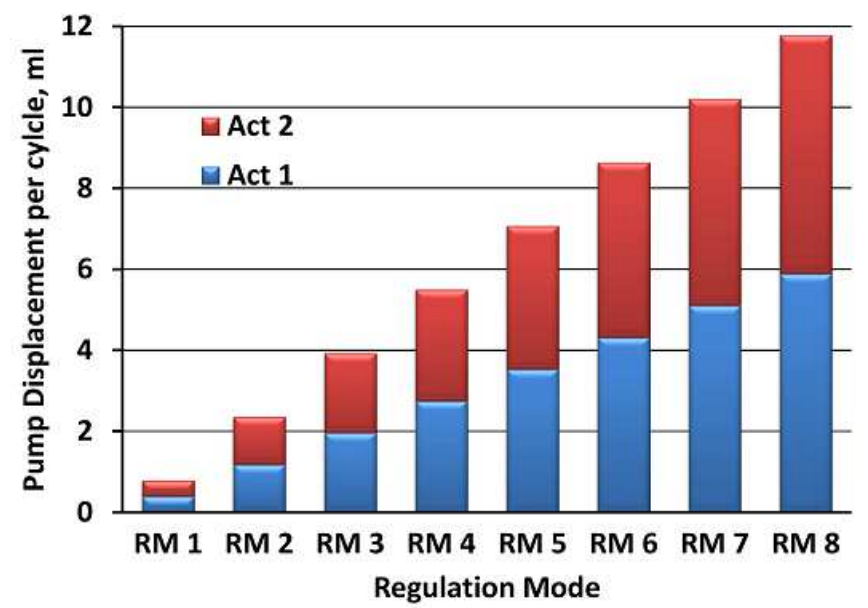

Figure 7. Piston displacement vs. regulation mode for single-act and double-act LBIP.

Fig. 7 shows piston displacement of both single-act and the developed double-act LBIP versus the 8 regulation modes. The simple regulation facility enables the double-act LBIP to cover wide range of displacement from $10 \mathrm{~mm}(0.8 \mathrm{ml})$ to 150 $\mathrm{mm}(11.8 \mathrm{ml})$ per cycle.

Changing regulation mode is accomplished by using suitable combination between the 3 adapters that shown in Fig. 6. Pump discharge depend not only on the regulation mode but also on the 3 -way control valve cyclic speed. Fig. 8 shows the pump curves of nominal pump discharge as a function of valve cyclic speed for the 8 different regulation modes. The two control facilities (regulation mode and/or valve speed) provide a wide range of injection capacity (20-1000 liter/day). Line bleeding amount should be drained from the line. This bleed amount is depending on the driving piston to injection pistons area ratio of, 2.25 for this design.

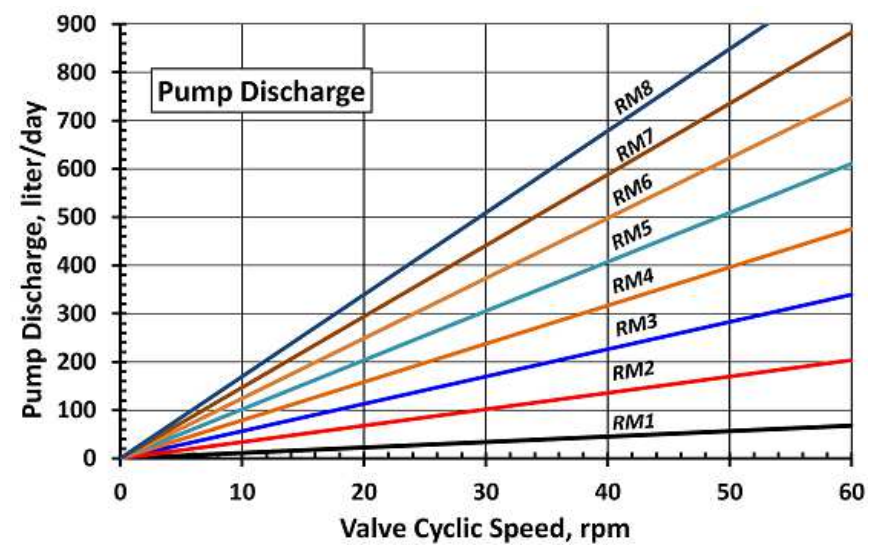

Figure 8. Effect of valve cyclic speed on pump nominal discharge at various regulation modes.

Fig. 9 shows the effect of the regulation modes and valve cyclic speed on line bleeding for double-act LBIP. 


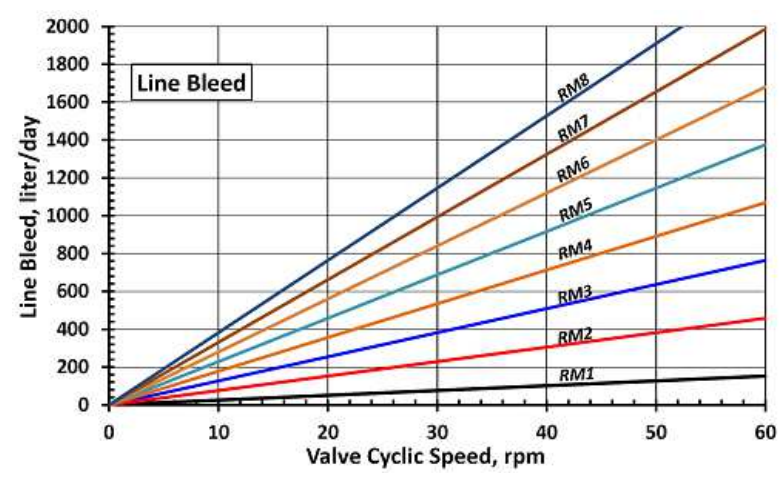

Figure 9. Effect of valve cyclic speed on line nominal bleed at various regulation modes.

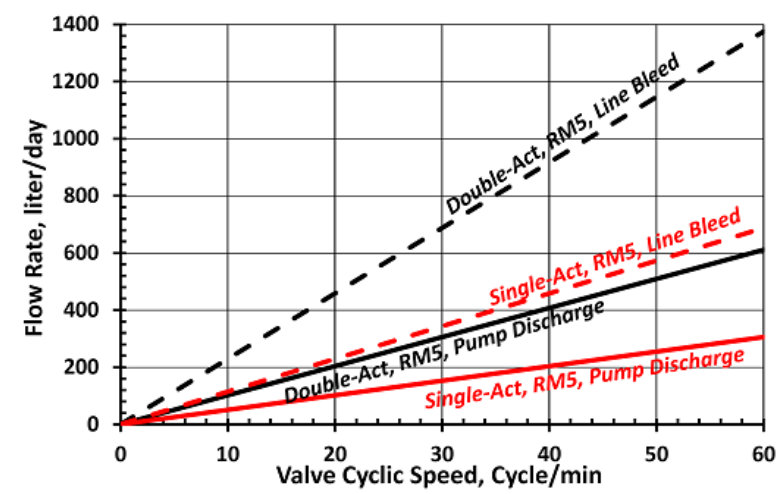

Figure 10. Effect of valve cyclic speed on pump nominal discharge and line nominal bleed at $\mathrm{RM}_{5}$ regulation mode for both single-act and double-act LBIP.

Fig. 10 shows a comparison between the pump bleed and the pump discharge for $\mathrm{RM}_{5}$ regulation mode for both single-act and double-act LBIP. Increasing area ratio increases pressure of injection and enhances time response of the pump at the expense of increasing the amount of pump bleed. This parameter should be further optimized through experimental investigations. After some operating period, the fluid in the bleeding tank at certain level could be easily pumped back to the line using appropriate pump like centrifugal pump for moderate pressure injection or piston pump for high pressure injection. Time response is also important parameter that depends on area ratio, friction forces between piston seals and cylinder and other parameters. Higher control valve cyclic speed may cause piston movement time response to be slower than valve cyclic speed which will cause mismatch of control device. Time response parameter should be experimentally investigated.

\section{Conclusion}

3D-CAD shows a feasibility of the developed double-act LBIP concept. The developed pump provides simple and low price facility with wide control range of pump injection. It provides further step towards a mature novel design and facility for injection pumps that used in the water production market. Double-act LBIP covers a wide range of injection flow (20-1000 liter/day) using compact and simple variable displacement control facility with high accurate metering injection process. The simple design and materials used for double-act LBIP takes the price to very competitive low value compared to conventional types available in the market. As an example, PVC materials could be used for aggressive chemicals in case of moderate pressures with low temperature applications.

The developed design requires no spring action for suction stroke. Suction stroke is driven by delivery stroke of the other piston end (Action 1 drives suction of Action 2 and vice versa). The driving power of the LBIP is only the line pressure itself. Renewable energy seawater desalination researches and plants in remote areas may urgently need such concept of no driving electricity or fuel requirements.

Both single-act and double-act LBIP designs needs to be prototyped and investigated carefully. The performance of the double-act LBIP and its added value to the injection pump market should be investigated. Some important parameters should be further intensively investigated. Such parameters are: piston ends area ratio, piston injection end diameter, driving and controlling facility to the 3-way control valve and piston time response and its time delay and the interaction with valve cyclic speed limitations.

\section{Acknowledgments}

Acknowledgments to Deanship of Scientific Research, University of Hail, Saudi Arabia for funding and supporting the single-act LBIP project code (E8 ME, $1^{\text {st }}$ round) which opens the door for this development of the double-act LBIP.

\section{Nomenclature}

$\begin{array}{ll}\text { LBIP } & \text { Line Bleeding Injection Pump } \\ \mathrm{PVC} & \text { Polyvinyl chloride } \\ \mathrm{AD}_{1,2,3} & \text { Adapters } 1,2 \text { and } 3 \\ \mathrm{RHS} & \text { Right Hand Side } \\ \text { LHS } & \text { Left Hand Side } \\ \mathrm{RM}_{1,2-8} & \text { Regulator Modes } 1,2, \ldots \text { and } 8 \\ \mathrm{~V}_{1,2} & \text { 3-way valves } 1 \text { and } 2 \\ \mathrm{NV}_{1,2,3,4} & \text { Non-return Valves } 1,2,3 \text { and } 4 \\ P_{L} & \text { Line pressure } \\ P_{I} & \text { Injection pressure } \\ F & \text { Piston force } \\ A_{L} & \text { Line side cross sectional area } \\ A_{I} & \text { Injection side cross sectional area } \\ \Delta X & \text { Piston displacement, mm } \\ \Delta V & \text { Volume displacement, ml/stroke }\end{array}$

\section{References}

[1] United Nations 2001. The State of World Population. World Population Prospects: The 2000 Revision: Highlights. New York: Population Division, Department of Economic and. Social Affairs. 2001 
[2] http://en.wikipedia.org/wiki/Desalination

[3] H. Ettouny and L. Rizzuti. Solar Desalination: Challenge for Sustainable Fresh Water in the 21th Century. Springer. 2007, pp 1-18.

[4] H. Murrenhoff. Grundlagen der fluidtechnik teil 1: Hyraulik. Umdruck zur Vorlesung. Shaker Verlag GmbH. Germany. 2005.

[5] Product news. WORLD PUMPS. September 2014.
[6] V. A. Kurteev. Diaphragms for pneumatic pumps. Chemical and Petroleum Engineering. Vol. 47, Nos 7-8, 2011, pp. 550-556

[7] S. Reynolds. Fully MR-compatible syringe pump for the controllable injection of hyperpolarized substrate in animals. Springer Verlag, Applied Magnetic Resonance, 2012

[8] Mohamed Elashmawy. Novel Injection Concept: Line Bleeding Injection Pump (LBIP). Science Innovation. Vol. 2, No. 4, 2014, pp. 37-42. doi: 10.11648/j.si.20140204.11 